\title{
THE TESI PROJECT AS ONE OF THE WAYS TO PREVENT SOCIAL ISOLATION OF PEOPLE WITH VERBAL COMMUNICATION DISORDERS
}

\author{
Mirosław Babiarz ${ }^{1}$
}

\begin{abstract}
The content of this article concerns an important issue, which is the search for optimal educational solutions for children with communication disorders. The article presents the whole idea and main goals of the TESI project, that is an Adaptive Personalized System for Creating Expression Tools in Social Inclusion of Learners with Verbal Communication Disabilities, which focuses on social integration of people with verbal communication disorders that are at risk of social isolation. It is dedicated to the conceptualization and development of social competence related to personal, social and professional development of people with verbal communication disorders through the creation of an adaptive, affordable and easy-to-use software solution that will enrich their personal expression opportunities. The article presents the main goals of the TESI project, among which the most significant one is to ensure the ability to express oneself fully.
\end{abstract}

UDC Classification: 376, DOI: 10.12955/cbup.v7.1387

Keywords: education, special needs, support, inclusion, social integration, TESI

\section{Introduction}

"Speech is a very delicate instrument and even the smallest dysfunctions affect it unfavorably" (Kozłowska 2004). Speech serves to discover the world, make contacts or express emotions and needs. Any developmental disturbances in the form of negative deviations from the norm have their consequences for the development of speech and the process of efficient communication. Inhibition in reception as well as the transmission of sensory impressions and their processing, poor vocabulary, speech defects, hearing impairments impede the child's normal cognitive and emotional process and, above all, hinder his/her socialization process. It is estimated that there are over 60 million people in the European Union affected by communication disorders - characterized by difficulties in using language and communication skills. Moreover, in the contemporary world, people live longer and dynamic progress in the field of medical sciences gives more and more chances of survival for individuals who have suffered from accidents or illnesses, thus the number of people with communication disorders will continue to grow. Therefore, today's work with people with disabilities (in particular with disorders of the communication process) is both a social and educational challenge.

\section{The TESI Project}

Language development is a complex, dynamic process that is conditioned by the biological and social development of the individual, and especially the development of their individual experiences in relationships with the environment. The need to communicate is an important need of each person, because it allows communication, which has a development function but also satisfies basic mental needs such as: belonging, love, emotional contact, and recognition. In the case of disturbances in communication and in particular lack of verbal contact, alternative methods of communication are used. There are numerous non-verbal methods of communication that find application in relationships with people with different levels of communication capabilities. The most popular ones are selected and discussed briefly in this paper. Firstly, Polish sign language - it is the language of deaf people who have their own visual-spatial grammar. An important role in communication with the use of this method is played by the hands, facial expressions and other signals transmitted in space. It is used to improve information exchange with people with extensive verbal communication disorders and develop their communication skills.

Secondly, sign language system - based on a combination of sign language and Polish sign language, based on the Polish language grammar, which allows deaf people to build correct statements.

Thirdly, Makaton Language Program - applies to people with serious disorders in verbal communication, including people with autism, Asperger's syndrome and is used to learn how to communicate. It is a system of gestures and graphic symbols containing over 350 terms from the everyday area and 700 concepts in the field of extended vocabulary. Each concept is supported by the appropriate manual character (gesture) and / or graphic image (symbol). This method occurs in many versions adequate to the language system of a given country.

\footnotetext{
${ }^{1}$ Jan Kochanowski University, Faculty of Pedagogy and Arts, Kielce, Poland, mirco@interia.pl
} 
The fourth method is the Bliss alternative communication system. It is a system based on drawings as graphic representations of specific statements. The dictionary includes 3,000 symbols representing over 6,000 words that let the users name a specific object as well as an abstract concept. The system allows building sentences, whole statements reflecting experiences, emotions, experiences, which promotes the development of the child's personality. It is designed to communicate with people who do not speak or their speech is very poorly developed or not very clear (mental disability, cerebral palsy, autism, dysarthria, aphasia).

The fifth method is pictograms - it represents words or concepts. The symbol is white and placed on a black square with the word above it. This system has 2,000 symbols, including $2 \%$ of ideograms (conceptual similarities to abstract concepts). It is adapted to the cultural conditions of the language. It is used to develop communication in people with intellectual deficits, with problems related to language understanding and practical use. These are simple and effective ways of establishing communication with people who have problems in language communication (they do not speak, do not understand speech, do not understand social situations, children with learning disabilities and impaired visual and auditory perception).

The sixth method is Pictogram Communication Symbols (PCS). It is a collection of drawings conveying the meaning of the basic words, necessary for everyday communication. Abstract words are expressed in specific symbols. It is available in many language versions and also in a computer version. It works well in the process of communicating with people affected by periodic inability to communicate verbally.

The seventh method is Dactylography (finger method). It is a form of communication based on appropriate finger palms, where each letter or number corresponds to a specific dactylographic sign. In this method, grammar rules are maintained (Eckert, 2001).

The literature of the subject distinguishes three groups of people who need to improve the communication process. In the first group are those with linguistic expression disorders who have the ability to understand speech, but are unable to use it (children with cerebral palsy, people with slight mental disability). Their difficulties are connected with the process of articulation, creating and extracting words due to various disorders, delays in the development of speech or damage to speech mechanisms. The second group embraces people who need to support their development with various dysfunctions and the associated difficulties in verbal and written communication (children with specific difficulties in reading and writing - developmental dyslexia) or periodic problems with verbal communication. People who need support through the use of alternative communication methods constitute the third group. In their case, the lack of verbal communication or its significant limitation is associated with a low level of development and speech understanding (people with intellectual dysfunction to a large extent, deep and deaf people). Their communication is based on sound signals and non-verbal behaviours. It is important that some children need to combine forms of verbal communication support, taking into account the changing needs in the area of communication and general development of the individual.

Language development disorders influence the process of reasoning and speech, and, consequently, hinder social development and building interpersonal relations. These disorders mainly concern the difficulties in effective communication using the language system. They may also have a different character, which is mainly due to the type of disorder. These may be the articulatory (expressive) difficulties, phonetic and phonological difficulties or difficulties in understanding speech or its creation in accordance with the rules of the mother tongue. In people with special educational needs, verbal communication disorders occur in the following forms:

a) Aphasia (total impossibility of speaking);

b) Lack of speaking and using speech in social relations (internal speech) in people with autism or intellectual dysfunction in a deep degree;

c) Disorders of verbal communication in children with intellectual dysfunction (oligophasia);

d) Dyslalia or incorrect articulation of sounds - includes elisions, substitutions or distortions in children with delayed speech development of various etiologies, in children at risk of developmental dyslexia; 
e) Dysarthria, which occurs in children with cerebral palsy (difficulties in speaking out or even in extracting a voice);

f) Inconsistency of statements, lack of logical reasoning in people with Asperger syndrome (problems concern building statements, understanding messages with good knowledge of words);

g) Disorders of auditory perception as a result of damage to brain structures - aphasia (difficulty with naming objects, understanding speech), there is also a disturbance of phonemic hearing found in children at risk or developmental dyslexia;

h) Speech fluency disorders (stammering).

Communication problems occur in a large group of people with intellect dysfunction, sensory disorders, autism or cerebral palsy. In addition to axial symptoms resulting directly from a specific dysfunction, these people have difficulty with verbal communication in the areas of speaking, writing and reading. Lack of verbal contact hinders or prevents them from communicating effectively with the environment and the learning process. It is characterized by: incorrect articulation, too weak vocabulary, presence of agrammatism (a type of physical aphasia manifested by speech disorders resulting in the violation of the grammatical form of the spoken words), problems with building sentences, too slow or fast speech rate, too quiet or too loud speech or speech without intonation. The list of developmental disorders with language and communication problems should be mentioned:

- Down syndrome and intellectual disabilities;

- $\quad$ Speech and Language Impairment;

- Autism;

- Developmental delays:

- Language or speech;

- Social and emotional skills;

○ Thinking or cognitive skills;

For instance, people with autism show communication difficulties in all parts of speech, i.e. in phonological, syntactic, semantic and pragmatic areas, so using speech in social situations.

Verbal communication disorders are the cause of segregation, isolation and even exclusion of people from peer, family, social and professional life as well as are the source of functional difficulties. The model of inclusive education creates unique opportunities because it ensures in the education process full participation of all students, regardless of gender, social and economic status, race, place of residence, disability, age or religion. Adaptive Personalized System for Creating Expression Tools in Social Inclusion of Learners with Verbal Communication Disabilities, which is named the TESI project, number 592177-EPP-1-2017-1-BGEPPKA3-IPI-SOC-IN, is the answer that gives the possibility of social integration of people with verbal communication disorders at risk of social isolation. The international TESI project was implemented in 2018 and will terminate in 2019 year. 8 partners collaborate on this project. These are 4 universities: Plovdiv University "Paisii Hilendarski" PU, UNED - the Spanish University for Distance Education (Universidad Nacional de Educación a Distancia), University of Craiova (UCV) and the Jan Kochanowski University in Kielce (JKU), 3 schools: Scoala Gimnaziala Speciala Sf. Mina Craiova (Mina), the Josip Matos Primary school (OSMatos) and the Special School for Students with Hearing Impairments "Stoyan Belinov" - Plovdiv (CHD), 1 association: the Association for Education and Development of Disabled People (ASEDDEDIPE). The project involves scientists, teachers, interdisciplinary specialists, parents and self-advocates from various organizations and institutions. People involved in this initiative come from different backgrounds - both national and cultural - and have a wide range of skills and work experience with people with special educational needs and disabled people. Team members use their experience and knowledge to develop a model of expression tools, emotions and needs based on a set of drawings and pictures, collected to correspond to everyday functioning with the help of which the users will be able to communicate effectively.

The main aim of the TESI project is to create and develop a tool for people (children and adults) with language communication disorders and implement solutions developed for educational and social practice. The created tool is intended for mobile devices and can be downloaded from Google apps. Anyone who wants to use this tool can download it and install it on their mobile device (phone or tablet). The next step will be to register via the appropriate website as a user, select the appropriate 
language and enter the data in the admin panel (parent, teacher, etc. - a working person, supporting a person with difficulties in the communication process) and the data of the person with whom the TESI tool / application will be used (people with difficulties in the communication process).

Then, the person using the panel will be able to create expressions (defining the needs, expectations, emotions, feelings, etc.) for the user (people with difficulties in the communication process) and expressions / instructions (parent, teacher). Their purpose will be to inform the user about the required action and how to properly perform it. The functioning of the tool will be based on the database of images / drawings, which each user and parent, teacher, etc. can freely build by adding any images available on the device or on the internet. After adding the appropriate picture / pictogram, it will be necessary to name a given picture (object, action). As a result, after selecting (clicking) a required picture by the user, parent or teacher, a voice message will be heard, explaining what is shown in the picture. The TESI tool will work in all languages of the project partners.

The TESI project is currently at the most important stage of its implementation, as all project partners are piloting the TESI tools. Taking an example of the Jan Kochanowski University, 19 students of pedagogy (selected according to the previously assumed criteria) participated in the training meetings about the TESI tool, and are prepared to use it while working with children at a pre-school age who have difficulties in the communication process. One of the aims of these meetings is to assess both the very tool (its strengths and weaknesses as well as the difficulties and opportunities) and the child's work with the TESI tool (in the emotional and motivational areas as well as the cognitive and bahavioral ones). The results of all partners' pilot phase are to be known at the end of November, 2019.

The created tool will be used to improve the communication process of a person with the broadly understood environment, including the transmission of messages, expressing their own needs and expectations, expressing emotions and feelings, informing about internal states, building statements and creating descriptions. The TESI tool eliminates the communication barrier, contributes significantly to the development of social skills and social integration.

The use of modern technologies and digital resources gives new opportunities for effective educational and social integration, in the following ways:

a) modern technologies give teachers freedom in communication and presentation of their needs and emotions;

b) the use of modern technologies eliminates limitations related to time, place and quantity of information materials;

c) the use of technology does not require earlier preparation, especially for young people. Interactive tools are often intuitive and offer very good opportunities for personal expression.

The TESI project focuses on the development of social competences, especially in the field of language and speech, enriching interpersonal skills, and thus also personal and social development, allowing people to express their needs, emotions and feelings more effectively. The TESI project refers to the long-term priorities of the Europe 2020 strategy, both in socio-economic and training objectives, addressed to disadvantaged social groups - vulnerable to poverty and social exclusion, and underlines the role of inclusive education in a radical improvement of opportunities life. The European Disability Strategy (2010-2020) shows the "business case" for inclusion both in terms of employers' benefits from having such people in the labor market and for nations in terms of positive gains that can be achieved by improving education for these people in unfavorable situation, thereby increasing the likelihood that they will grow up as employees paying taxes and not dependent on state benefits.

An important issue in the learning process is the connection, integration of popular and widely used electronic technologies, mainly with the possibilities offered by various types of devices, including primarily mobile devices. The main beneficiaries of the TESI project will be: persons with verbal communication disorders, parents, carers, teachers, educators, psychologists and auxiliary staff. In a long-term: authorities, decision-makers in the field of special education, managing educational institutions, members of local communities.

\section{Conclusions}

The created tool will be used to improve and facilitate the communication process, including the transmission of messages, expressing needs, emotions, feelings, expectations, and building statements. 
The most important goals of the TESI as an alternative communication tool are to build social integration and develop pro-social behaviours, raise awareness of self-activity (nie wiem co oznacza to określenie) in the development process and overcome barriers and limitations in life. The main benefits of the proposed solutions within the TESI project are primarily a simple and available application that uses computer technology, which increases the attractiveness of activities, especially in children, as well as the ability to create different image configurations, which facilitates the development of thinking, word resources and, consequently, speech.

\section{References}

Adaptive Personalized System for Creating Expression Tools in Social Inclusion of Learners with Verbal Communication Disabilities TESI PROJECT Number 592177-EPP-1-2017-1-BGEPPKA3-IPI-SOC-IN.

Eckert U., Pedagogika niestyszacych i niedostyszacych- surdopedagogika [Pedagogy of deaf and hard of hearing surdopedagogy], w; Pedagogika specjalna [Special education], red. W. Dykcik, Wydawnictwo UAM, Poznań 2001.

Kozłowska K., Logopeda bliżej dziecka [A speech therapist closer to the child], Kielce 2004. 